\title{
Machine Vision Course for Manufacturing Engineering Undergraduate Students
}

\author{
Jose Macedo, Kurt Colvin, and Daniel Waldorf, Industrial and Manufacturing Engineering, \\ California Polytechnic State University, San Luis Obispo, California, USA
}

\begin{abstract}
A 10-week course was designed with funding from the Society of Manufacturing Engineers (SME) and input from industry representatives, to offer upper division engineering students a course on advanced automation. The objective was to provide engineering students theoretical and handson practical experience with automation technologies that will be of prime importance over the next decade: data acquisition and instrumentation, machine vision and motion control. This paper describes the machine vision portion of that class. It describes important concepts, hands-on equipment, and labs developed for this course, as well as examples of student projects from Spring Quarter, 2004. The course and laboratory materials were evaluated for learning effectiveness and technical content, which are included in this paper.
\end{abstract}

Keywords: Machine Vision, Image Processing, CCD Cameras, Automation, Laboratory

\section{Introduction}

Computer vision, as the field that studies the automated analysis of images and video sequences, started in the 1950 s. For many years it was a research subject, mostly within computer science. During the past 10 years, computer vision has changed dramatically. It has become an accepted technology with many successful industrial applications. The applications-oriented subset of this field is referred to as machine vision. These changes have occurred due to several factors: the growth in computing processor and bus speed, growth in memory capacity, significant cost reduction of computer and machine vision technologies, and the availability of powerful and easy-to-use machine vision software tools.

The Automated Imaging Association (AIA) estimates that more than 53,000 vision systems were sold in North America in 2004 for a total of \$1.9 billion USD (Kellett 2005). The AIA estimates that the number of systems sold will reach 72,000 by 2008 , with an annual increase of slightly over $10 \%$. AIA attributes the current growth to the increasing awareness among manufacturing companies of successful and cost-effective applications of machine vision technology that have led to improvements in productivity and quality.

Currently, several equipment manufacturers offer standard equipment with integrated machine vision systems. This is the case in surface-mount technology pick-and-place equipment for electronics assembly, as well as metrology instruments such as optical coordinate measurement machines (CMMs).

Current applications of machine vision are in the following industries: electronics, metal, automotive, wood, plastics, paper, textiles, films, food manufacturing, and biomedical. Common functions are: recognition of features or components; guidance of assembly, robotic arms or vehicles, welding, or dispensing; and inspection, measurement, and detection of defectives. The objectives of the applications are typically improved quality, better placement accuracy, faster processing, higher productivity, reduction of human error, reduction of setup time or cycle time, and improve cost effectiveness.

Future manufacturing engineers need to be aware of machine vision technology, so they can realize the opportunities to integrate this technology into other processes where it is not currently available. The authors believe the opportunities to apply this technology will be abundant. The future manufacturing and assembly of micro and nano components will require manufacturing systems with optical methods for guidance, process control, and inspection. Also, nonmanufacturing applications of machine vision are becoming common, such as character recognition, biometrics and face recogni- 
tion, biological and medical applications, surveillance for security, defense, and space exploration.

Several manufacturing engineering and other programs have developed courses in machine vision in the last few years. Bebis, Egberg, and Shah (2003) produced a comprehensive review of computer vision courses in science and engineering programs. Otieno and Mirman (2002) and Liang (1996) describe machine vision courses developed as part of manufacturing engineering technology programs. Zhuang and Sudhakar (2003) developed a machine vision laboratory that is used to support several engineering courses, including a freshman introduction to engineering course. Broussard and Armstrong Piepmeier (2004) have developed a course on machine vision for senior systems engineering students at the United States Naval Academy that is designed to complement an existing robotics course. Shiver, Needler, and Cooney (2003) describe an automation course that includes machine vision in addition to programmable logic controllers, using LabVIEW ${ }^{\infty}$ software for data acquisition and control and DVT software for machine vision. Joyner et al. (2004) and Edinbarough and Bose (2004) describe capstone design projects in which teams of senior students integrated inspection systems including machine vision, programmable logic controller, robot, conveyors, and actuators. Joyner et al. used DVT software for machine vision, and Edinbarough and Bose used Matlab $^{\circ}$. Yeh and Hammond (2002) describe an industry project developed by students in which machine vision was successfully integrated to guide a robot manipulator in a tire rim factory.

At Cal Poly, the content of the second automation course (IME-356) was revised in 2003 to offer upper-division manufacturing engineering students further experience with advanced automation. The result was a 10-week course designed with $\$ 7,200$ of funding from a Society of Manufacturing Engineers Education Foundation grant and input from industry representatives. The objective was to provide future engineers with theoretical and hands-on practical experience with automation technologies that will be of prime importance over the next decade: data acquisition and instrumentation, machine vision, and motion control. This paper describes the machine vision portion of that class, as well as concepts, hands-on equipment, and labs developed for this course. Examples of student projects from spring quarters 2004 and 2005 are included to demonstrate the level of sophistication the students attained.

\section{Details of the Course}

The course objectives for the machine vision portion of this class were that by the end of the class, students should be able to:

- Describe the components of a machine vision systems, their functions, and the various technological options available for them.

- Be familiar with the most common image processing algorithms used in industrial applications.

- Identify situations or systems that could be improved by the application of machine vision.

- Identify and select the machine vision components suitable for an intended application.

- Design or integrate machine vision into a manufacturing system.

Because this course was developed for manufacturing engineering senior students, several implementation topics were included. For example, selection of lenses, illumination, or integration are not normally included in computer vision or image processing courses offered in computer science or other engineering programs. The lecture topics for the machine vision portion of this class are listed below:

Machine Vision Lecture Topics

- Introduction to machine vision system

- Cameras (sensors) and camera selection

- Lenses and lens selection

- Illumination

- Image capture

- Image processing

- Implementation, integration, signal I/O

- Application examples

The specific image processing techniques included in the course were selected based on the most common applications of machine vision in industry. The image processing topics included in this class are listed as follows:

Image Processing Techniques

- Coordinate systems

- Regions of interest

- Histograms and thresholds

- Blob analysis and morphology

- Filters

- Edge detection

- Pattern matching, identification 
- Color image processing

- Camera calibration

- 3-D machine vision techniques

One of the prerequisites for this class is an automation class (IME 356), in which students learn about automation with programmable logic controllers (PLCs), sensors, actuators, and ladder-logic programming. All of the students had taken a structured computer programming language course, but none had ever been exposed to the LabVIEW software used in this class.

The class was structured as two hours of lecture and three hours of laboratory weekly for a 10-week quarter. Due to lab development costs, the first offering of the class was designed with six workstations accommodating 12 students working in pairs. By allowing flexible access to the lab, enrollment increased to 14 students in spring 2004.

The laboratory was based on National Instruments (NI) products for the following reasons: the preexistence of a site license for all NI software, including LabVIEW, and modules for machine vision, motion control, and data acquisition; NI software is easy to learn and use; NI software and hardware work well together; and NI products are also used in nonacademic environments.

For the machine vision portion of the class, students were provided with electronic copies of NI manuals on machine vision (IMAQ 2003) and the textbook on digital image processing by Ertürk (2003) published by NI. NI allows distribution of these materials to students, thus students did not need to purchase a textbook.

The class and laboratory was designed so that students would have hands-on experience, in part because Cal Poly has an established tradition of "learning by doing" and also because solving problems and experiencing successes in a lab setting creates a deeper level of understanding. A laboratory with six identical machine vision workstations was created. An existing computer lab was modified to include six sets of CCD cameras, lenses, light fixtures, and dimmer controls purchased with funding from the SME Education Foundation. The lab technicians built camera stands. The laboratory equipment for the machine vision portion of this class is listed below:

Machine Vision Laboratory Equipment

- Computer PC with IEEE 1394 interface

- Software: NI LabVIEW
- Software: NI Vision Assistant

- Software: NI IMAQ for 1394

- CCD camera IEEE 1394 (firewire)

- C-mount 12-mm lens

- Lens extension rings kit

- Light fixture with dimmer control

- Fabricated stand for camera and light

Figure 1 shows a machine vision workstation, and Figure 2 shows a section of the laboratory. Currently, there are several choices for the technology for the cameras, such as analog vs. digital cameras, and use of a frame-grabber interface card (for either an analog or digital camera) or a simpler IEEE 1394 interface card. Also, there is a choice between CCD or CMOS camera sensors and between monochrome and color cameras. The decision to use IEEE 1394 (firewire) cameras was made because there is no need for a frame grabber; therefore, the lab can be run in almost any computer lab. Color cameras were used so that topics and exercises on color image pro-

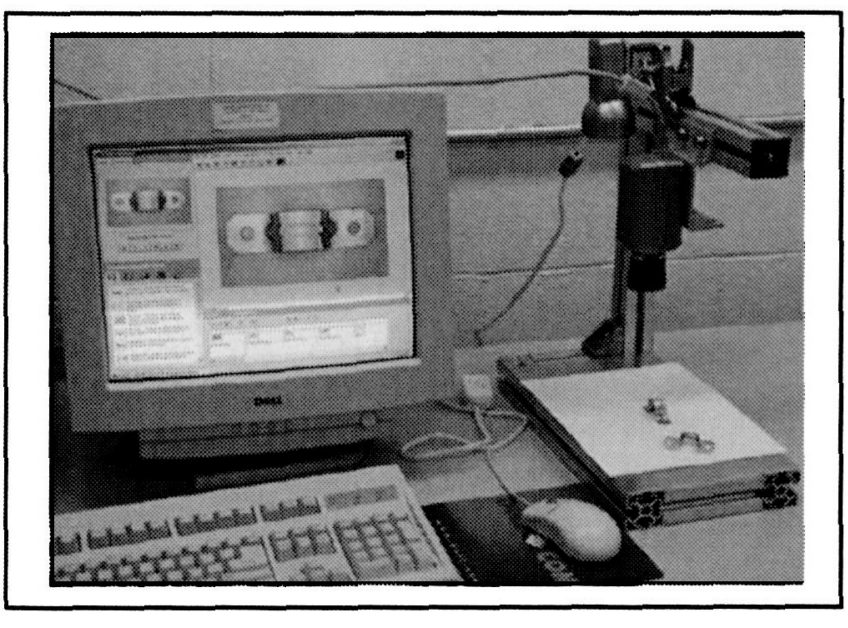

Figure 1

Machine Vision Workstation

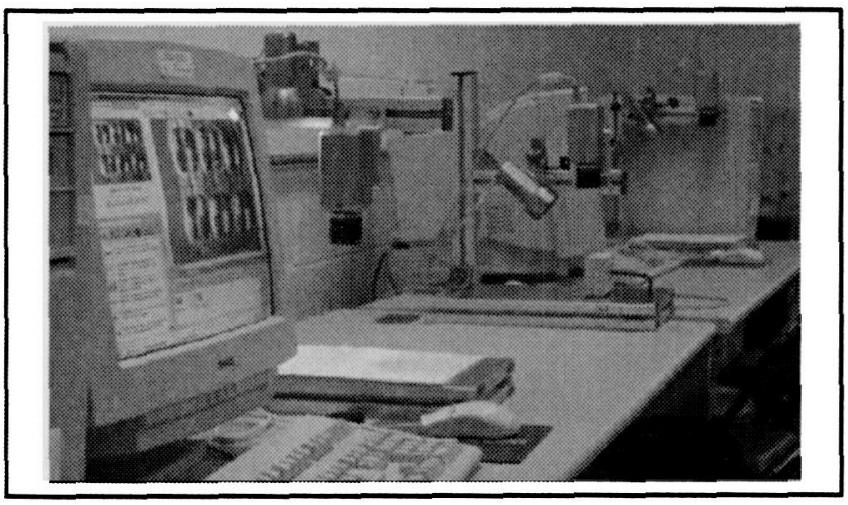

Figure 2

View of a Section of the Laboratory 
cessing could be included. The lab was equipped for approximately $\$ 1,200$ per machine vision workstation, not including computers or the NI software.

Labs consisted of a progression of steps with increasing difficulty. Students began with a tutorial portion and demo exercises. These were followed with challenge problems in which they were expected to apply the concepts demonstrated to solve a problem. For example, after a hands-on demonstration of color image processing algorithms, color matching, and identification, students were given a package of $\mathrm{M} \& \mathrm{M}^{\circledR}$ candies and asked to develop a program to count and display the number of candies of each color being presented to the camera. They could only eat the candy after showing to the instructor that their program worked effectively.

The following are the laboratory topics over the 10 weeks:

\section{Laboratory Exercises}

1. Introduction to LabVIEW.

2. Data acquisition and $A / D$.

3. State-machine programming in LabVIEW.

4. Introduction to machine vision, lenses, illumination.

5. Pattern matching, coordinate systems.

6. Vision calibration and metrology application.

7. Color machine vision.

8. Introduction to motion control.

9. Integration of motion and vision.

10. Project presentations.

Table I shows a more detailed list of weekly topics covered in lectures and labs.

Student grades were based on completing weekly labs and developing a project during the quarter. Students worked in teams of two for both the weekly

Table 1

Machine Vision and Image Processing Course Topics and Schedule

\begin{tabular}{|c|c|c|}
\hline Week & Lecture & Laboratory \\
\hline 1 & $\begin{array}{l}\text { Introduction to Data Acquisition Systems, } \\
\text { controllers, sensors review. }\end{array}$ & $\begin{array}{l}\text { Introduction to LabVIEW programming. VI's, } \\
\text { data types, program flow, structures. }\end{array}$ \\
\hline 2 & $\begin{array}{l}\text { Applications of data acquisition. Analog and } \\
\text { and Digital Signal review. Signal Processing, } \\
\text { sampling, resolution, ADC/DAC. }\end{array}$ & $\begin{array}{l}\text { Programming of data acquisition system. Timing } \\
\text { considerations, disk file output. }\end{array}$ \\
\hline 3 & $\begin{array}{l}\text { State machine diagrams, event-driven } \\
\text { sequential control of systems. }\end{array}$ & State machine programming in LabVIEW. \\
\hline 4 & $\begin{array}{l}\text { Machine Vision System Overview. Cameras } \\
\text { (sensors) and camera selection. Lenses and } \\
\text { lens selection. Illumination. Image capture. }\end{array}$ & $\begin{array}{l}\text { Assemble camera and lenses. Image capture, } \\
\text { illumination. LabVIEW and Vision Builder } \\
\text { introduction. Image histogram, line scan, edge } \\
\text { detection, blob analysis. }\end{array}$ \\
\hline 5 & $\begin{array}{l}\text { Image processing: regions of interest, } \\
\text { histograms, thresholds and filters, blob } \\
\text { analysis and morphology, edge detection, } \\
\text { coordinate systems, pattern matching, } \\
\text { identification. }\end{array}$ & $\begin{array}{l}\text { Pattern matching, scripting and program development. } \\
\text { Part inspection: size or feature, classify as } \\
\text { defective or conforming. }\end{array}$ \\
\hline 6 & $\begin{array}{l}\text { Camera calibration, 3-D machine vision } \\
\text { techniques. Color image processing. }\end{array}$ & $\begin{array}{l}\text { Calibration in 2-D, size measurement, position } \\
\text { measurement. reference frame. }\end{array}$ \\
\hline 7 & $\begin{array}{l}\text { Implementation, integration, signal } \mathrm{V} / \mathrm{O} \text {, } \\
\text { application examples, synchronization } \\
\text { and timing. }\end{array}$ & $\begin{array}{l}\text { Color matching, triggered image acquisition, } \\
\text { signal output, turntable example, strobe light, } \\
\text { synchronization. }\end{array}$ \\
\hline 8 & $\begin{array}{l}\text { Introduction to Motion Control Systems, } \\
\text { motors, drives, motion controllers. Types } \\
\text { of motion control systems. }\end{array}$ & $\begin{array}{l}\text { Wiring of servo system, single axis (brushed } \\
\text { motor). Introduction to motion programming. }\end{array}$ \\
\hline 9 & $\begin{array}{l}\text { Position and velocity feedback. Mechanical } \\
\text { transformation, direct drive, gears, gear } \\
\text { boxes, lead screws. }\end{array}$ & $\begin{array}{l}\text { Configure second axis (brushless). Programming } \\
\text { motion profiles/loops. Homing, limit switches } \\
\text { and } \mathrm{I} O \mathrm{O} \text {. }\end{array}$ \\
\hline 10 & $\begin{array}{l}\text { Design topics: load inertia calculation, } \\
\text { system sizing, component sizing, natural } \\
\text { frequency issues. }\end{array}$ & Project presentations. \\
\hline
\end{tabular}


labs and the projects. There were assigned readings and homework assignments. There was no exam for the course.

\section{Student Projects}

Students were asked to develop a project in which they were expected to apply concepts learned in this class. All projects were self-selected. Students were encouraged to generate their own ideas for a project and to discuss these ideas with the instructors. There are some benefits as well as potential difficulties of using this approach.

The biggest benefit of self-selected projects is the high level of enthusiasm and motivation of the students once they start working on their ideas. Students want to make their project idea work and will come to the lab more frequently to ensure the success of their project.

A potential difficulty is that students unfamiliar with the technology may find it difficult to select a project idea. If the indecision is carried too far into the term, there may not be adequate time to develop or complete a quality project. Providing examples of project ideas, especially past projects for the same class, allows students to more easily move forward.

Students were asked to prepare a poster about their project and make a brief informal presentation in class at the end of the quarter. The presentations were useful to all students as examples of other applications, methods used, problems encountered, lessons learned, and to discuss possible future enhancements of the projects. The posters have been useful to show past projects to the second group of students as well as to visitors.

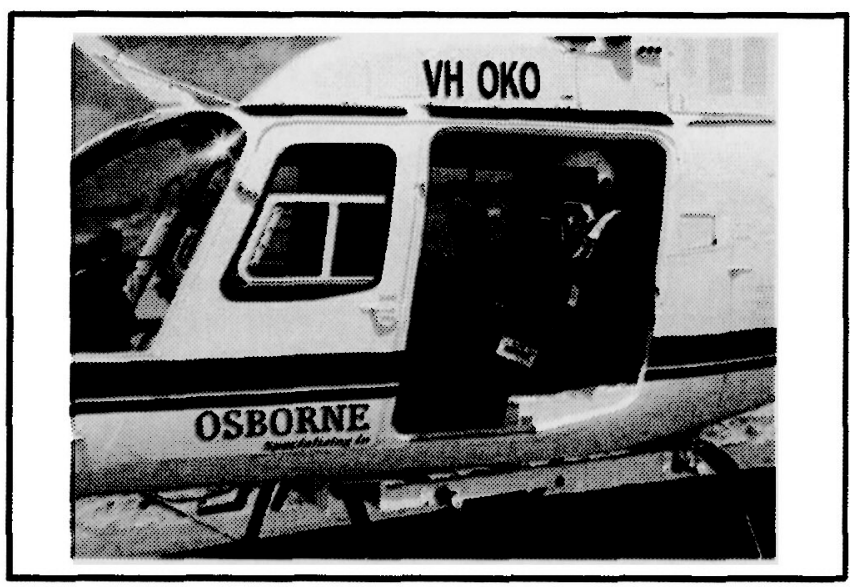

Migure 3

Infrared Comern System for Fire Detection from a Helfeopter
The next two sections describe briefly the project topics developed by students during the past two course offerings. A total of 20 students developed 10 projects. All of the projects were successful in meeting their initial objectives, and in many cases the projects were enhanced with additional features. Summaries of the student projects follow.

\section{Student Projects in Spring 2004}

Fire detection and location using images from infrared cameras obtained from a helicopter

This project was inspired by the summer job of one of the students on the team. The student worked for a company spots fires for the forest service. The students obtained video files from the infrared camera system shown in Figure 3 and developed a computer image processing program to automate the identification of fires. Figure 4 shows the computer program user interface developed by the students. The student project was successful. At the end of the quarter, the student made a presentation to his summer job company, which led to the company acquiring NI hardware and software to produce self-contained automated systems.

Three-dimensional scanning and measurement of objects using laser-structured light

Students developed a height measurement system by projecting a laser beam and placing a camera at an angle, as shown in Figure 5. The students developed the computer image processing program and calibrated the system to measure objects in inches or millimeters.

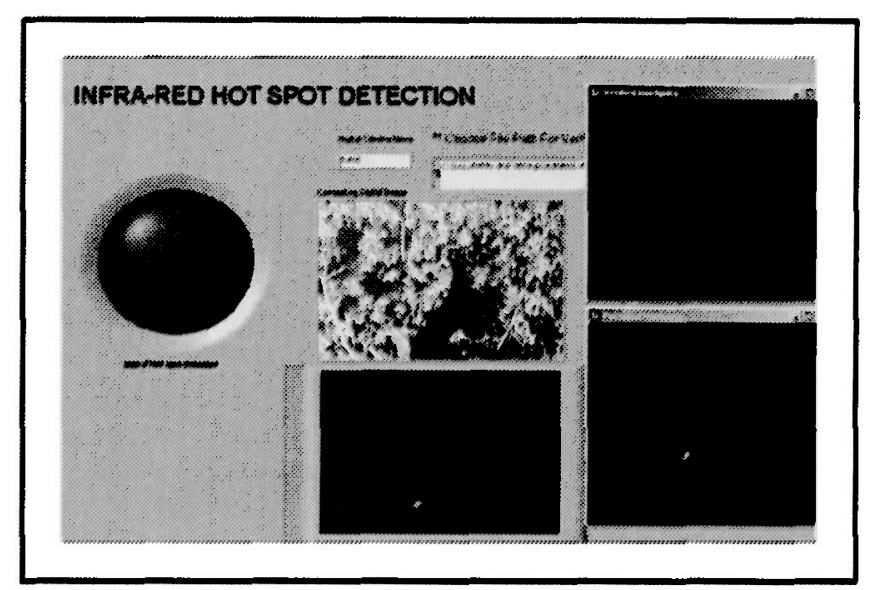

Figure 4

Computer Processing of Infrared Images for Mire Detection 


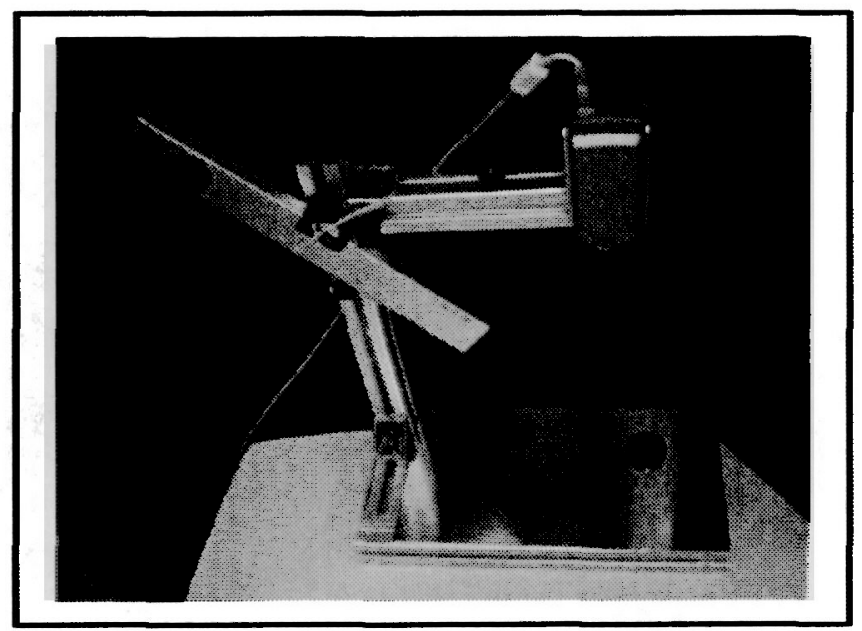

Fin 5

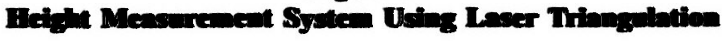

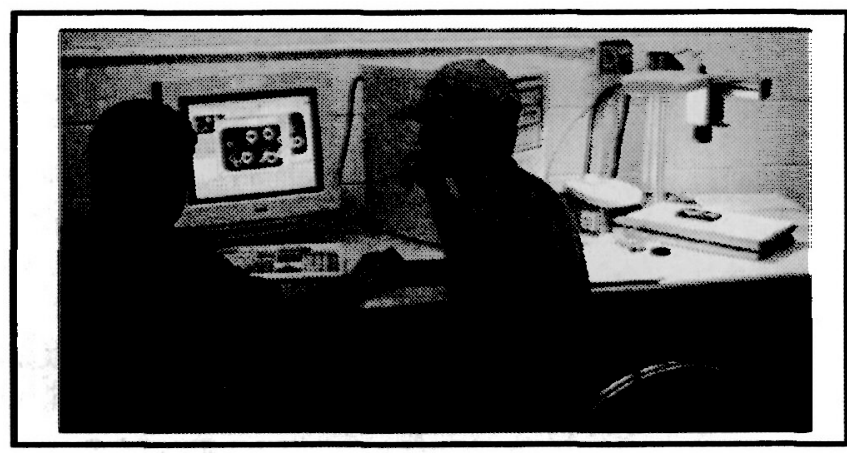

Fitine 6

Sinders Develering the Sythe for

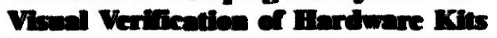

Visual verification of completeness on handware kits using a bill of materials image database

The students shown in Figure 6 developed a machine vision system that would capture and analyze images of hardware kits. These kits are small packages of nuts, bolts, screws, and washers that are included with items that are shipped disassembled. The computer image processing program developed by the students was capable of verifying if various different kit models were complete (no parts missing or in excess) by using a kit model bill of materials image database.

Automated calibration of proximity sensors using vision-based position measurements and a stepping motor

A student wanted to automate the process of calibrating an analog proximity sensor. The setup for manual calibration is shown in Figure 7. A potential problem with the automated system was that the sensor needed proper alignment or the calibration would

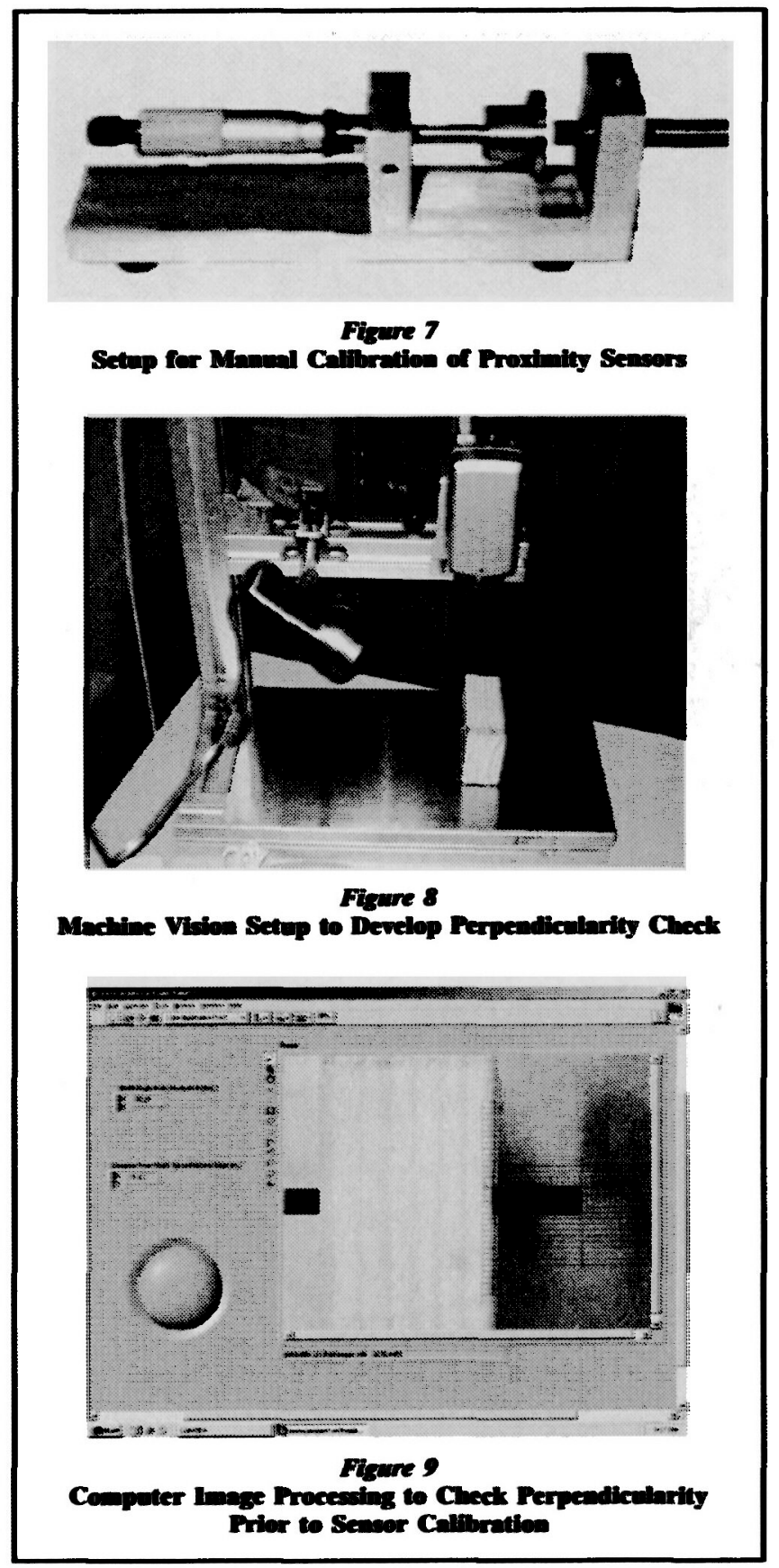

be faulty. The machine vision system was developed to verify that the sensor was placed perpendicular to the mounting bracket. Figures 8 and 9 show the machine vision setup and computer program user interface developed by the student.

Surveillance and intruder detection by analysis of image sequences

A student wanted to develop a machine vision system for surveillance and intruder detection. The system developed compared all consecutive pairs on a 


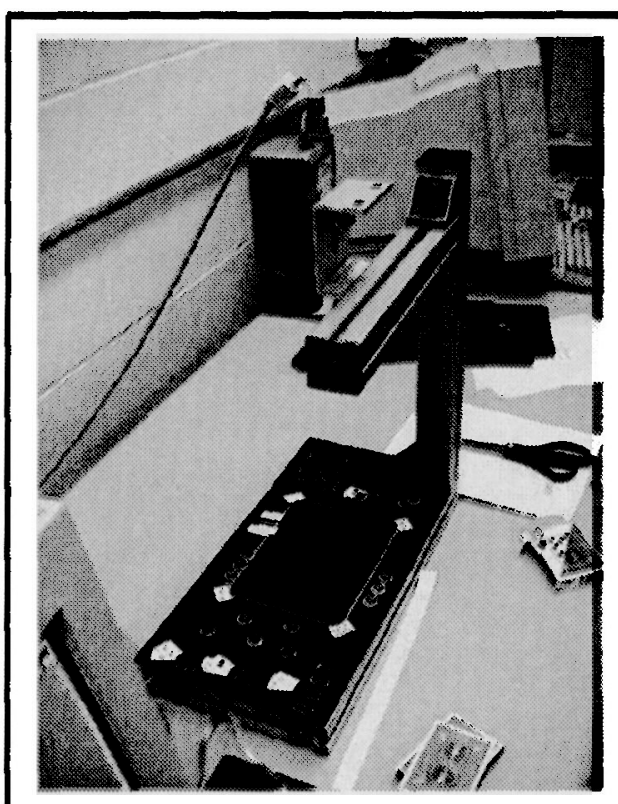

Flaure 10

Machine Vision setup for an Autemated Blackjack Card Game

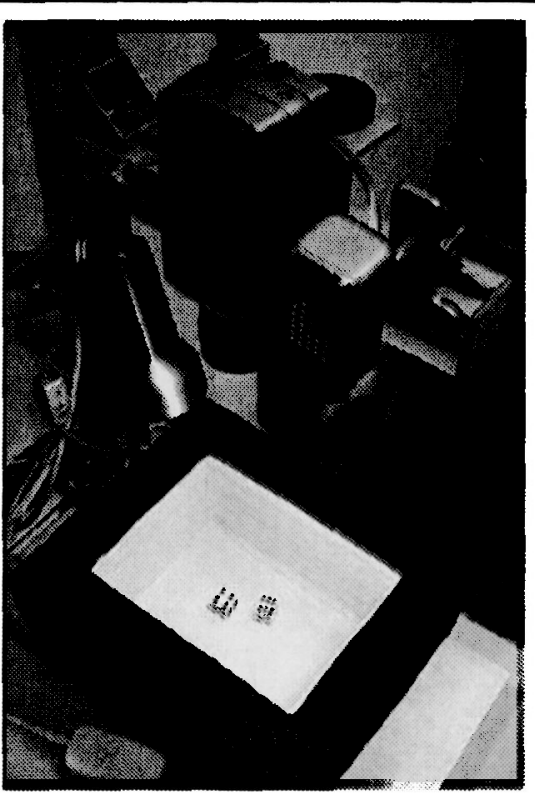

Floure II

Machine Viden Sotup for Automated "Craps" Dice Game

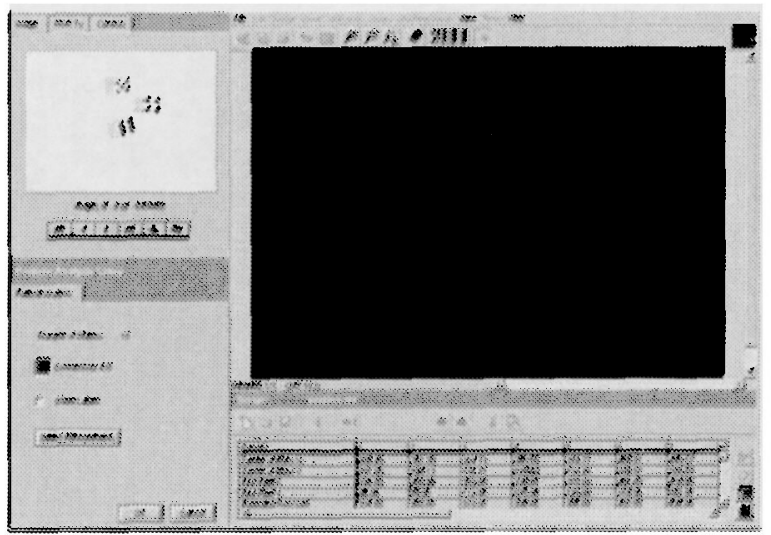

Fisure 12

Computer Image Procesting of Automated "Crapg" Dice Game

stream of images captured by a camera. It recorded images and coordinates of any changes detected.

Automated "card" game using machine vision, image processing, and pattern recognition

Students developed a machine vision system to automate the blackjack card game. Figure 10 shows the machine vision setup developed by the students.

Automated "craps" game using machine vision, image processing, and pattern recognition

Students developed a machine vision system to automate the "craps" dice game. Figures $I I$ and 12 show the machine vision setup and a test computer program developed by the students.

\section{Student Projects in Spring 2005}

Hand signal recognition displaying written text on the computer screen

Students developed a machine vision system to recognize American sign language finger spelling by using back-lit illumination. Figure 13 shows the setup developed by the students. The system was developed to identify a new hand signal every few seconds and aggregate the letters to form words on the computer screen. Figure 14 shows the computer program user interface developed by the students.

Lie detection using a sequence of images of the eye measuring changes in pupil size

Students developed a machine vision system to detect lies by measuring changes in eye pupil size. Figure 15 shows the setup developed by the students. Immediately following a "true/ false" question to a volunteer, the system captured 10 images of the eye, measured the pupil diameter on the 10 images, and calculated the range. Exceeding a threshold on this range is presumably an indication of a lie. Although it is uncertain if the system was effective at detecting lies, it did measure the pupil diameter 10 times in one second and reported if the range of diameters exceeded the threshold. During final presentations, discussion of future improvements of this system included extending the time from 1 second to 5 or 10 seconds, and the number of images processed from 10 to 50 to increase reliability.

Automated target scoring using the sum of the distances from each hit to target center

Students developed a machine vision system to automatically calculate the score of a target sheet. Figure 16 shows the setup developed by students. 


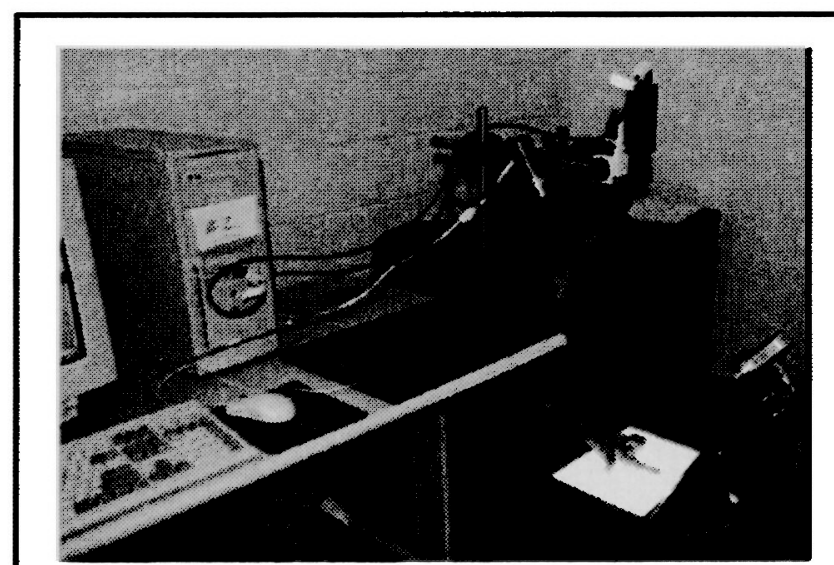

Bigure 13

Machine Vision Setup for Hand Sigan Recogation

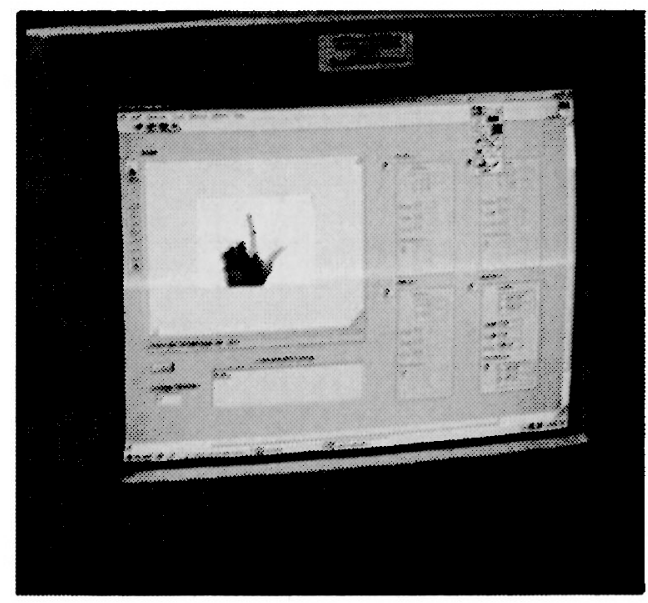

Floure 14

Computer Procesdies of Hasd Stgonl Recognition

The scores were calculated by measuring the distances of the "hits" to the center of the target sheet.

\section{Student Feedback and Assessment}

The course was well received by students. At the end of spring 2004 and 2005, anonymous surveys were conducted to assess various aspects of the course. Surveys included several questions regarding specific learning objectives to be answered using a 1-5 scale. Several open-ended questions addressed the students' perception of the value of the course. The tabulated results for the specific learning objectives are shown in Table 2.

Regarding the machine vision learning objectives, almost all students reported that their learning objectives improved "a great deal" or "significantly," with only one student reporting for

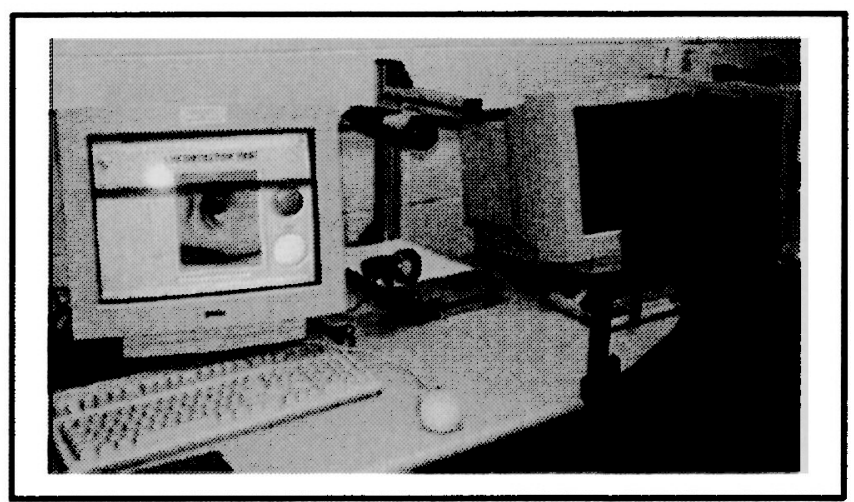

Plowre 15

Machine Vision Setup for Lie Detector Meacuring Chamges in Bye Pupll

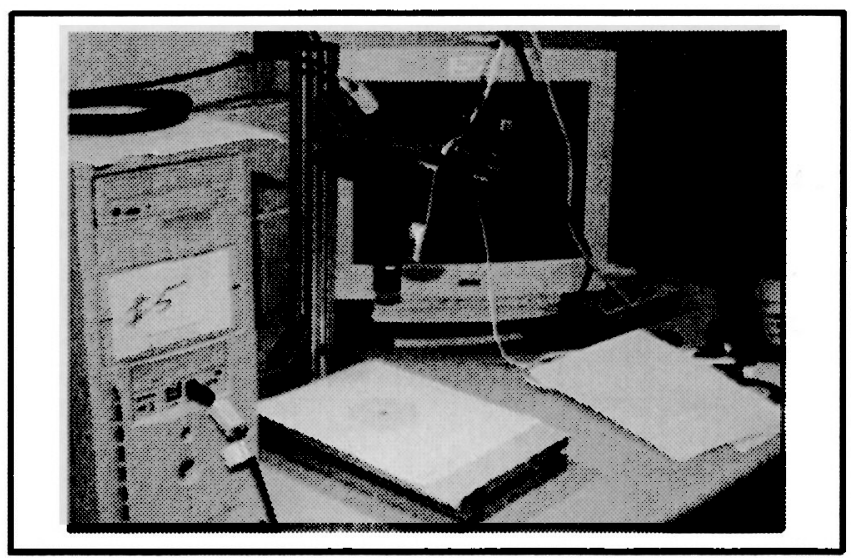

Flewre 16

Machine Vidon Setop for Automatic Tongt Scorton

item 1 that there was "somewhat" improvement. Students gave the highest scores to items 3 and 5 in Table 2, which refer to developing skills to: "identify situations or systems that could be improved by the application of machine vision," and to "design or integrate machine vision into a manufacturing system."

On the section of "Learning Specific Skills" (items 6-9), students gave the highest scores to items 6 and 9, which refer to becoming familiar with programming in LabVIEW and with image processing algorithms.

The open-ended question section of the survey asked students several questions, such as: "What from this course is the most useful?" and "What from this course is the least useful?" A variety of very positive and useful answers were obtained. Students' answers to the question: "Would you recommend this course to another engineering student?" was unanimously "yes." 
Table 2

Student Assesment Results - Combined Spring 2004 and 2005

(number of responwes in each category, and percent)

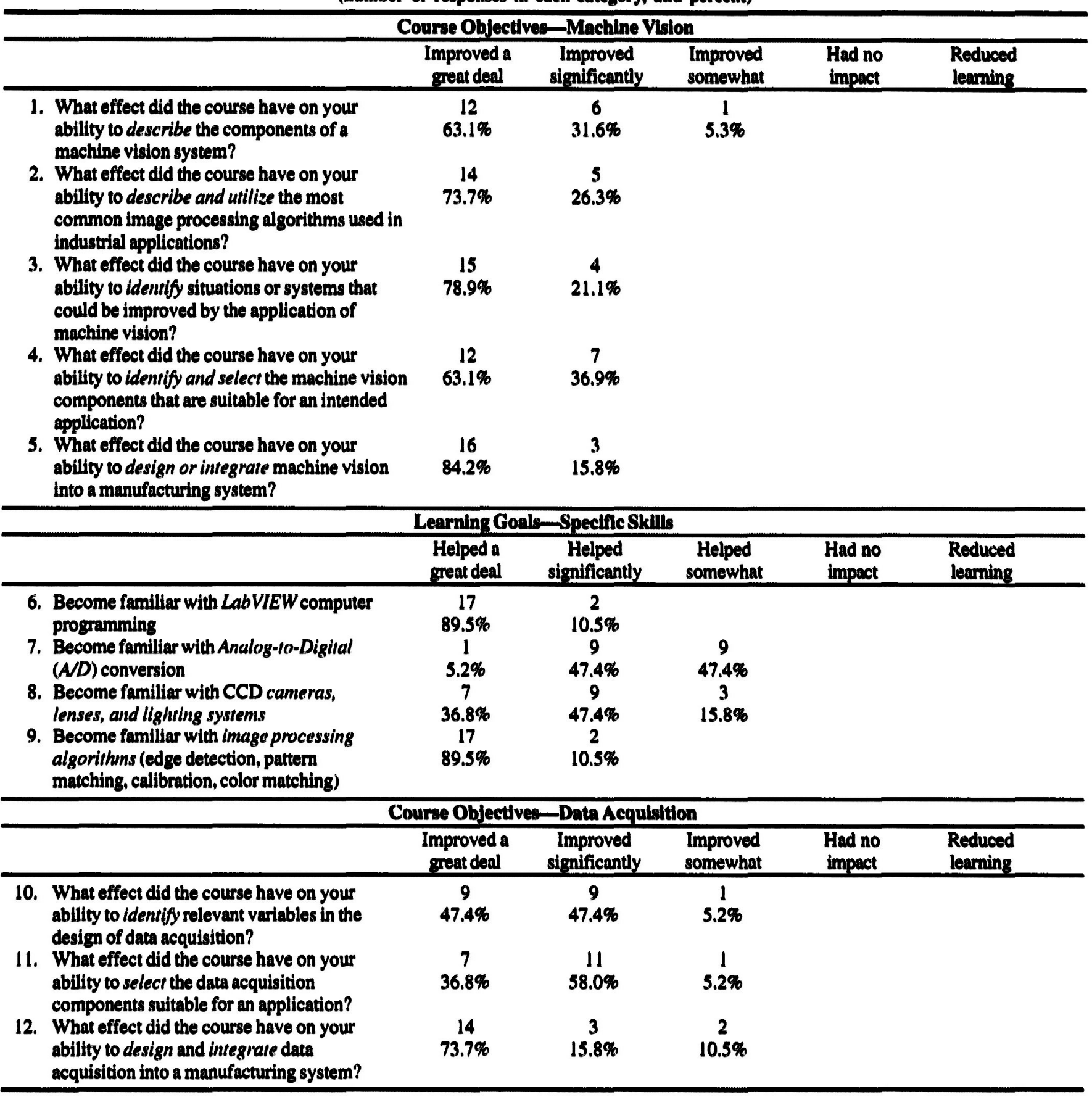

\section{Planned Course Improvements}

The planned improvements of this course include integrating vision and motion by adding the NI software Motion Assistant and creating new experiments.

Another goal is increasing the number of students taking this class by advertising it as a technical elec- tive to other engineering disciplines. With an increase in the number of students, an increase in the number of workstations to accommodate up to 24 students would be implemented.

Developing lab manuals and drafting a textbook will make these materials available beyond the $\mathrm{Cal}$ Poly campus. 


\section{Conclusions}

A 10-week course was designed to offer upperdivision engineering students further experience with advanced automation. The objective was to provide future engineers with theoretical and hands-on practical experience with automation technologies that will be of prime importance over the next decade: data acquisition and instrumentation, machine vision, and motion control. The course was offered for the first time in spring quarter 2004. The course and laboratory materials were evaluated for learning effectiveness and technical content. The results indicate that students' perceptions of their learning experience were very good. Students developed self-selected projects working in teams of two. All of the projects were completed successfully, which is an indication that students were able to meet course objectives, specifically to be able to design and integrate machine vision into a system to meet specific goals. Judging by the quality of the student projects, the learning objectives were met and the class was a success.

\section{References}

Bebis, G.; Egberg, D.; and Shah, M. (2003). "Review of computer vision education." IEEE Truns. on Education (v46, n1), pp2-21.

Broussard, R. and Armstrong Piepmeier, J. (2004). "Undergraduate computer vision curriculum to complement a robotics program." Proc. of 2004 ASEE Conf.

Edinbarough. I. and Bose, S. (2004). "A vision and robot based online monitoring of defects in electronics manufacturing - a collaborative effort in capstone project." Proc. of 2004 ASEE Conf.

Entirk, S. (2003). "Digital image processing." Part Number 323604A01. National Instruments Corp.

IMAQ (2003). "IMAQ vision concepts manual." Part Number 322916B-01. National Instruments Corp.

Joyner, K.; Shipman, J.; Mott, B.: Harper, D.; Morris, E.; and Eslami, A. (2004). "A capstone design project - machine vision system in inspection process." Proc. of 2004 ASEE Conf.

Kellett. P. (2005). "Machine vision markets." Automated Imaging Association (AIA). May 2005, www.machinevisiononline.org.
Liang, Z. (1996). "Teaching robot vision in manufacturing technology." Proc. of 1996 ASEE Conf.

Otieno. A. and Mirman, C. (2002). "Machine vision applications within a manufacturing engineering technology program." Proc. of 2002 ASEE Conf.

Shiver, A.; Needler, M.; and Cooney, E. (2003). "Integrating data acquisition tools to accomplish an automation course project." Proc. of 2003 ASEE Conf.

Yeh, C. and Hammond, H. (2002). "An industry based student project: implementing a machine vision system for robotic application." Proc. of 2002 ASEE Conf.

Zhuang, H. and Sudhakar, R. (2003). "Development of a machine vision laboratory." Proc. of 2003 ASEE Conf.

\section{Authors' Biographies}

Jose A. Macedo is an associate professor of industrial and manufacturing engineering at California Polytechnic State University in San Luis Obispo. He received his $\mathrm{PhD}$ in industrial engineering from Lehigh University. His research interests are in machine vision and image processing and manufacturing automation. He has taught courses on statistical design and analysis of experiments, quality engineering. machine vision, robotics, manufacturing automation, and manufacturing processes. During the summers of 2000 and 2001, he worked with the machine vision group at the Jet Propulsion Laboratory (JPL-NASA) in Pasadena, CA. He is a registered professional engineer in the state of Texas and has engaged in consulting with the following companies: Boeing. Honeywell, lomega, Texas Instruments. Toro, and Sequenom.

Kurt Colvin is an associate professor of industrial and manufacturing engineering at California Polytechnic State University in San Luis Obispo. He received his $\mathrm{PhD}$ in industrial engineering from from Oregon State University. His research interests are in human factors. He has more than five years of continuing collaboration with NASA Ames Research Center performing human factors eye-tracking research on pilots. He has taught a wide variety of both IE and MfgE courses. He is currently teaching design and manufacturing, material joining, and industrial automation.

Dan Waldorf is an associate professor of industrial and manufacturing engineering at California Polytechnic State University in San Luis Obispo. He received his $\mathrm{PhD}$ in industrial engineering from the University of Illinois at Urbana-Champaign. His research interests are in machining rool wear and vibration modeling and monitoring, and advanced cutting tool design. He has engaged in consulting work in quality control and reliability. He has taught mainly in the manufacturing processes area, including manufacturing process design, tool engineering, advanced process design, net shape processing, computer-aided manufacturing, quality engineering, and manufacturing engineering analysis. 